\title{
PENGARUH KOMUNIKASI INTERPERSONAL TERHADAP KINERJA PEGAWAI PADA KANTOR KECAMATAN JAWILAN KABUPATEN SERANG
}

\author{
Lutfiya Illah ${ }^{1}$, Achmad Nashrudin $\mathbf{P}^{2 *}$, \\ ${ }^{1,2}$ Universitas Bina Bangsa \\ *nashrudin.achmad@gmail.com
}

\begin{abstract}
ABSTRAK
Untuk mencapai tujuan organisasi, pada suatu instansi pemerintah dibutuhkan kinerja baik dan terukur. Agar kinerja pegawai dapat dicapai dengan baik diperlukan komunikasi yang intens antar pegawai. Dalam melaksanakan tugas pelayanan publik sesuai tugas dan fungsinya pegawai pada Kantor Kecamatan Jawila Kabupaten Serang, memerlukan kesamaan persepsi agar tujuan organisasi tersebut dapat tercapai. Kesamaan persepsi tersebut tercipta melalui komunikasi antar pegawai, yang disebut Komunikasi interpersonal. Penelitian ini bermaksud mengkaji pengaruh komunikasi interpersonal terhadap kinerja Pegawai pada Kantor Kecamatan Jawilan. Metode yang digunakan adalah pendekatan kuantitatif, dengan menggunakan metode pengumpulan data melalui kuesioner. Teknik pengambilan sampel menggunakan Teknik sampel jenuh dimana sampel sebanyak 40 orang. Jumlah sampel sama dengan jumlah populasi Selanjutnya penelitian menggunakan uji validitas (test of validity) dan uji reliabilitas (test of realiability). Hasil penelitian menunjukkan bahwa pengaruh komunikasi interpersonal yang terdiri dari keterbukaan, empati, dukungan dan rasa positif ditingkatkan maka meningkatkan kinerja pegawai. Berdasarkan hasil perhitungan Uji $\mathrm{T}$ yaitu hasil pengujian menunjukkan bahwa nilai signifikasi $=0,000<0,05$ atau nilai sig $\langle 0,05$ t hitung $\rangle$ t tabel $(5,983>2,024)$. Artinya $\mathrm{H}_{\mathrm{a}}$ diterima, dan $\mathrm{H}_{\mathrm{O}}$ ditolak, dan hasil koefisien korelasi ( $\mathrm{R}$ ) adalah $=0,746$, hubungannya sangat kuat antara Komunikasi Interpersonal dengan Kinerja Pegawai pada Kantor Keamatan Jawilan,, Kabupaten Serang. Serta hasil analisis regresi menunjukkan terdapat pengaruh positif antara variabel Komunikasi Interpersonal (X) dan variabel Kinerja Pegawai (Y) pada Kantor Kecamatan Jawilan, Kabupaten Serang, ditunjukkan dari persamaann regresi $\mathrm{Y}=6.929+0.652 \mathrm{X}$
\end{abstract}

Kata Kunci: Organisasi, komunikasi interpersonal, kinerja pegawai

\begin{abstract}
To achieve organizational goals, a government agency requires good and measurable performance. In order for employee performance to be achieved properly, intense communication between employees is required. In carrying out public service tasks according to the duties and functions of employees at the Jawilan District Office, Serang Regency, it requires a common perception so that the goals of the organization can be achieved. The common perception is created through communication between employees, which is called interpersonal communication. This study intends to examine the effect of interpersonal communication on employee performance at the Jawilan District Office. The method used is a quantitative approach, using data collection methods through questionnaires. The sampling technique used was the saturated sample technique where the sample was 40 people. The number of samples is the same as the total population. Furthermore, the study uses a test of validity and a test of reliability. The results showed that the effect of interpersonal communication consisting of openness, empathy, support and positive feeling was increased, thus increasing employee performance. Based on the results of the T-test calculations, the test results show that the significance value $=0.000<0.05$ or sig value $<0.05$ t arithmetic $>t$ table (5.983 > 2.024). This means that Ha is accepted, and HO is rejected, and the result of the
\end{abstract}


correlation coefficient $(R)$ is $=0.746$, the relationship is very strong between Interpersonal Communication and Employee Performance at the Jawilan District Office, Serang Regency. And the results of the regression analysis show that there is a positive influence between the Interpersonal Communication variabel $(X)$ and the Employee Performance variabel $(Y)$ at the Jawilan District Office, Serang Regency, as shown by the regression equation $Y=6.929+$ $0.652 X$

Keywords: Organization, interpersonal communication, employee performance

\section{PENDAHULUAN}

Kecamatan Jawilan meruapakan bagian dari wilyah Pemerintahan Daerah (Pemda) Kabuptaen Serang. Ada 29 Wilayah Kecamatan di Kabupaten Serang, Kecamatan Jawilan meruakan salah satunya (Sumber : https://jawilan.serangkab.go.id/).

Sebagai subordinasi dari Pemerintah Kabupaten (Pemkab) Serang, sudah barang tentu Kecamatan Jawilan bertanggungjawab daam mensukseskan Visi dan Misi kepada Daerahnya. Berdasarkan hasil Pemilihan kepala Daerah (serentak) yang dilakukan pada Tahun 2019 lalu, Kabupaten Serang dipimpina oleh pasanagn Bupati RT. Tatu Chasanah, SE., M.Ak dan Wakil Bupati Drs. H. Pandji Tirtayasa, M.Si.

Visi dan Misi Kabupaten Serang adalah Terwujudnya Masyarakat Yang Berkualitas Menuju Kabupaten Serang Yang Agamis, Adil dan Sejahtera. Sedangkan Misinya : 1) Memantapkan Fungsi Dan Peran Agama Sebagai Landasan Moral Dan Spiritual Dalam Kehidupan Individu, Bermasyarakat Dan Bernegara; 2) Meningkatkan Kualitas Sumber Daya Manusia Yang Sehat, Cerdas, Berakhlakul Karimah Dan Berbudaya; 3) Meningkatkan Kuantitas Dan Kualitas Sarana, Prasarana Dan Fasilitas Pelayanan Dasar Disemua Wilayah; 4) Meningkatkan Pertumbuhan Ekonomi Berbasis Potensi Lokal Serta Memperkuat Struktur Perekonomian Daerah; 5) Meningkatkan Kualitas Pengelolaan Lingkungan Hidup; 6) Mengembangkan Kawasan Strategis, Cepat Tumbuh, Pesisir Dan Pulau-Pulau;

7) Meningkatkan Penyelenggaraan Tata Kelola Pemerintahan Yang Baik Serta Didukung Kondisi Sosial, Politik, Keamanan Yang Kondusif Dan Strategis.

Sedangkan tugas dan fungsi (Tupoksi) Kecamatan adalah melaksanakan sebagian kewenangan pemerintah kabupaten di wilayah kerjanya, yang mencakup bidang pemerintahan, ekonomi, pembangunan, kesejahteraan rakyat dan pembinaan kehidupan masyarakat serta urusan pelayanan umum lainnya yang diserahkan Bupati.

Untuk menyelenggarakan tugas sebagaimana pada tersebut diatas, Kecamatan mempunyai fungsi: a) Pengorganisasian penyelenggaraan pemerintahan diwilayah kecamatan; b) Penggorganisasian kegiatan pembinaan dan pengembangan perekonomian rakyatdan melakasanakan pemungutan pendapatan daerah sesuai dengan kewenangan yang dilimpahkan; c) Penyelenggaraan 
Prosiding The 1st National Conference on Applied Business, Education, \& Technology (NCABET)"

Unversitas Bina Bangsa 2021

DOI Article : 10.46306/ncabet.v1i1.16

pelayanan sosial kemasyarakatan dan pemberdayaan masyarakat; d) Pembinaan kelurahan; e)

Pelaksanaan dukungan administrasi di bidang pendidikan sekolah dasar; f) Pembinaan ketentraman dan ketertiban wilayah kecamatan; g) Pelaksanaan koordinasi, operasional unit pelaksana teknis dinas / badan;dan h) Pelaksanaan fasilitasi kegiatan pembangunan dan pengembangan partisipasi masyarakat. Secara singkat fungsi Kantor Kecamatan sebagai salah contoh bentuk organisasi Publik, dalam hal ini organisasi pemerintahan adalah tugas Pelayanan Publik. Maka sebagai organisasi publik/pemerintah, komunikasi meruapakan hal yang sangat penting dan tidak bisa dihindarkan. Baik komunikasi dengfan para pegawai, dalam rangka saling mendukung untuk tercapainya proses pelayanan publik dan tercapainya efektifitas tugas dan fungsi yang melekat sebagai pelayan publik. Tercapainya tugas dan fungsi pelayanan publik dapa dilakasanakn dengan baik, dan berkualitas meruapakan pencapaian atas kinerja pegawai.

\section{METODE PENELITIAN}

Dalam penelitin ini metode yang digunakan adalah metode kuantitatif asosiatif. Metode asosiatif adalah suatu pertanyaan penelitian yang bersifat menanyakan hubungan antara dua variabel atau lebih (Sugiyono, 2015). Sedangkan populasi (N) dalam penelitian ini adalah seluruh pegawai Kantor Kecamatan Jawilan Kabupaten Serang yang berjumlah 40 pegawai. Teknik pengambilan sampel dalam penelitian ini menggunakan teknik sampel (n) jenuh yang menjadikan semua anggota sebagai sampel $(\mathrm{N}=\mathrm{n})$.

Adapun Teknik pengumpulan data dilakukan melalui data primer dan data sekunder. Data primer diperoleh melalui penyebaran kuesioner. Adapun data sekunder diperoleh melalui dokumendokumen dan sumber pustaka yang relevan (buku, dokumen yang sesuai dengan kebutuhan penelitian, data yang diperoleh melalui browsing dari sumber yang valid dan resmi. Seperti website pemerintah berbasis go.id dan jurnal-jurnal yang bereputasi).

Penelitian ini dilakukan di Kantor Kecamatan Jawilan Kabupaten Serang. Dalam penelitian ini terdapat $40 \mathrm{sampel/responden} \mathrm{pegawai} \mathrm{dengan} \mathrm{status} \mathrm{PNS.} \mathrm{Hingga} \mathrm{akhir} \mathrm{penelitian} \mathrm{ini}$ dilakukan, responden yang mengembalikan angket penelitian adalah 40 orang atau 100 persen dengan mengisi angket secara lengkap. Dengan demikian, secara metodologis dikatakan layak untuk dilakukan pengujian dan pembahasan hasil penelitian.

\section{a. Komunikasi Interpersonal $(\mathrm{X})$}

(Nashrudin P., 2011) mengtip Mulyana menyatakan "komunikasi antar pribadi (interpersonal communication) adalah komunikasi antara orang-orang secara tatap muka, yang memungkinkan setiap pesertanya menangkap reaksi orang lain secara langsung, baik secara verbal ataupun nonverbal". Komunikasi interpersonal dalam penelitian ini 4 indikator dan 10 item 
pertanyaan yang meliputi: keterbukaan (openess), empati (emphaty), dukungan (supportiveness) dan rasa positif (positiveness). Rekapitulasi jawaban responden terhadap komunikasi interpersonal dapat diuraikan sebagai berikut:

Tabel 1

Deskripsi Jawaban Terhadap Variabel Komunikasi Interpersonal (X)

\begin{tabular}{|c|c|c|c|c|c|c|c|c|c|c|c|c|c|}
\hline \multirow{2}{*}{$\begin{array}{l}\text { Indikator } \\
\text { variabel }\end{array}$} & \multirow{3}{*}{$\begin{array}{l}\text { Item } \\
\text { Butir } \\
\end{array}$} & \multicolumn{10}{|c|}{ Frekuensi (f) dan Persentase (\%) Jawaban Responden } & \multirow{3}{*}{$\begin{array}{l}\text { Rerata } \\
\text { (Mean) }\end{array}$} & \\
\hline & & \multicolumn{2}{|c|}{ STS (1) } & \multicolumn{2}{|c|}{ TS (2) } & \multicolumn{2}{|c|}{$\mathrm{N}(3)$} & \multicolumn{2}{|c|}{ S (4) } & \multicolumn{2}{|c|}{ SS (5) } & & \\
\hline \multirow{4}{*}{$\begin{array}{l}\text { Keterbukaan } \\
\text { (X1.1) }\end{array}$} & & $\mathrm{F}$ & $\%$ & $\mathrm{f}$ & $\%$ & $\mathrm{f}$ & $\%$ & f & $\%$ & $\mathrm{f}$ & $\%$ & & \\
\hline & $\mathrm{X} 1.1 .1$ & 0 & 0,00 & 0 & 0,00 & 1 & 2,5 & 15 & 37,5 & 24 & 60,0 & 4,58 & \multirow{3}{*}{4,64} \\
\hline & X1.1.2 & 0 & 0,00 & 0 & 0,00 & 1 & 2,5 & 12 & 30,0 & 27 & 67,5 & 4,65 & \\
\hline & $\mathrm{X} 1.1 .3$ & 0 & 0,00 & 0 & 0,00 & 1 & 2,5 & 10 & 25,0 & 29 & 72,5 & 4,70 & \\
\hline \multirow{3}{*}{ Empati (X1.2) } & $\mathrm{X} 1.2 .1$ & 0 & 0,00 & 0 & 0,00 & 2 & 5,0 & 15 & 37,5 & 23 & 57,5 & 4,52 & \multirow{3}{*}{4,63} \\
\hline & $\mathrm{X} 1.2 .2$ & 0 & 0,00 & 0 & 0,00 & 1 & 2,5 & 10 & 25,0 & 29 & 72,5 & 4,70 & \\
\hline & $\mathrm{X} 1.2 .3$ & 0 & 0,00 & 0 & 0,00 & 0 & 0,0 & 13 & 32,5 & 27 & 67,5 & 4,68 & \\
\hline \multirow{3}{*}{$\begin{array}{c}\text { Dukungan } \\
(\mathrm{X} 1.3)\end{array}$} & $\mathrm{X} 1.3 .1$ & 0 & 0,00 & 0 & 0,00 & 2 & 5,0 & 11 & 27,5 & 27 & 67,5 & 4,62 & \multirow{3}{*}{4,60} \\
\hline & $\mathrm{X} 1.3 .2$ & 0 & 0,00 & 0 & 0,00 & 0 & 0,0 & 18 & 45,0 & 22 & 55,0 & 4,55 & \\
\hline & $\mathrm{X} 1.3 .3$ & 0 & 0,00 & 0 & 0,00 & 1 & 2,5 & 13 & 32,5 & 26 & 65,0 & 4,62 & \\
\hline $\begin{array}{l}\text { Rasa Positif } \\
\text { (X1.4) }\end{array}$ & $\mathrm{X} 1.4 .1$ & 0 & 0,00 & 0 & 0,00 & 2 & 5,0 & 17 & 42,5 & 21 & 52,5 & 4,48 & 4,48 \\
\hline & \multicolumn{11}{|c|}{ Rerata Variabel Komunikasi Interpersonal (X1) } & \multicolumn{2}{|c|}{4,59} \\
\hline
\end{tabular}

Berdasarkan rekapitulasi jawaban responden atas variabel komunikasi interpersonal pada pegawai Kantor Kecamatan Jawilan seperti yang disajikan pada Tabel 4, menunjukkan bahwa deskripsi jawaban responden secara keseluruhan menyatakan sudah sangat baik dengan nilai rerata 4,59. Artinya bahwa mayoritas responden menyatakan secara keseluruhan mengenai penerapan komunikasi interpersonal meliputi: keterbukaan, empati, dukungan dan rasa positif sudah sangat baik.

\section{b. Kinerja Pegawai (Y)}

Kinerja adalah penilaian pegawai Kantor Kecamatan Jawilan atas hasil akhir dari aktivitas kerja yang dapat diukur melalui kemampuan kerja, kecakapan, keahlian dan sikap seorang pegawai dalam melaksanakan tugas. Kinerja diukur dengan 5 item pertanyaan yang terdiri dari kuantitas kerja, kualitas kerja, ketangguhan, kerja sama dan ketepatan waktu. Rekapitulasi jawaban responden terhadap kinerja diuraikan sebagai berikut:

Tabel 2

Deskripsi Jawaban Terhadap Variabel Kinerja Pegawai (Y)

\begin{tabular}{|c|c|c|c|c|c|c|c|c|c|c|c|c|}
\hline \multirow{2}{*}{$\begin{array}{l}\text { Indikator } \\
\text { variabel }\end{array}$} & \multirow{2}{*}{$\begin{array}{l}\text { Item } \\
\text { Butir }\end{array}$} & \multicolumn{10}{|c|}{ Frekuensi (f) dan Persentase (\%) Jawaban Responden } & \multirow{3}{*}{ Rerata (Mean) } \\
\hline & & \multicolumn{2}{|c|}{ STS (1) } & \multicolumn{2}{|c|}{ TS (2) } & \multicolumn{2}{|c|}{$\mathrm{N}(3)$} & \multicolumn{2}{|c|}{$\mathrm{S}(4)$} & \multicolumn{2}{|c|}{ SS (5) } & \\
\hline \multirow{6}{*}{ Kinerja (Y) } & & $\mathrm{f}$ & $\%$ & f & $\%$ & $\mathrm{f}$ & $\%$ & $\bar{F}$ & $\%$ & $\mathrm{f}$ & $\%$ & \\
\hline & Y1.1 & 0 & 0,00 & 0 & 0,00 & 1 & 2,5 & 26 & 65,0 & 13 & 32,5 & 4,30 \\
\hline & Y1.2 & 0 & 0,00 & 1 & 2,50 & 7 & 17,5 & 18 & 45,0 & 14 & 35,0 & 4,12 \\
\hline & Y1.3 & 0 & 0,00 & 0 & 0,00 & 22 & 55,0 & 15 & 37,5 & 3 & 7,5 & 3,52 \\
\hline & Y1.4 & 0 & 0,00 & 0 & 0,00 & 8 & 20,0 & 32 & 80,0 & 0 & 0,00 & 3,80 \\
\hline & Y1.5 & 0 & 0,00 & 0 & 0,00 & 7 & 17,5 & 28 & 70,0 & 5 & 12,5 & 3,95 \\
\hline & \multicolumn{11}{|c|}{$\frac{1}{\text { Rerata Variabel Kinerja (Y) }}$} & 3,94 \\
\hline
\end{tabular}

Berdasarkan rekapitulasi jawaban responden atas variabel kinerja pada Kecamatan Jawilan

Kabupaten Serang seperti yang disajikan pada Tabel 5, menunjukkan bahwa deskripsi jawaban 
Prosiding The 1st National Conference on Applied Business, Education, \& Technology (NCABET)"

Unversitas Bina Bangsa 2021

DOI Article : 10.46306/ncabet.v1i1.16

responden secara keseluruhan tentang kinerja menyatakan sudah sangat baik dengan nilai rerata

3,94. Artinya bahwa mayoritas responden menyatakan secara keseluruhan mengenai penerapan

kinerja meliputi: kuantitas kerja, kualitas kerja, ketangguhan, tanggung jawab dan ketepatan waktu sudah terlaksana dengan baik.

\section{c. Indikator Komunikasi Interpersonal}

Adapun indikator komunikasi interpersonal adalah sebagai berikut (Muhammad, 2014):

1. Keterbukaan (opennes)

2. Empati (empathy)

3. Dukungan (support)

4. Rasa positif (positiveness)

5. Kesamaan (equality)

Yaitu siap menerima anggota komunikasi lain sama atau setara

Tabel 3

Kisi-Kisi Instrumen Komunikasi Interpersonal

\begin{tabular}{|c|c|c|c|c|c|}
\hline Definisi & Indikator & $\begin{array}{c}\text { No } \\
\text { Butir }\end{array}$ & Jumlah & Instrumen & $\begin{array}{c}\text { Skala } \\
\text { pengukuran }\end{array}$ \\
\hline \multirow{6}{*}{$\begin{array}{l}\text { Menurut Arni Muhammad } \\
\text { "Komunikasi interpersonal } \\
\text { adalah pertukaran pesan } \\
\text { verbal maupun non verbal } \\
\text { antara si pengirim dengan si } \\
\text { penerima pesan untuk } \\
\text { mengubah tingkah laku. } \\
\text { Komunikasi interpersonal } \\
\text { merupakan proses pertukaran } \\
\text { informasi diantara seseorang } \\
\text { dengan paling kurang } \\
\text { seorang lainnya atau } \\
\text { biasanya diantara dua } \\
\text { orang." }\end{array}$} & Keterbukaan & 1,2 & 2 & \multirow{6}{*}{$\begin{array}{l}\text { Kuesioner } \\
\text { Skala } \\
\text { Likert } \\
\text { Instrumen } \\
1-5\end{array}$} & \multirow[t]{6}{*}{ Interval } \\
\hline & Empati & 3,4 & 2 & & \\
\hline & Dukungan & 5,6 & 2 & & \\
\hline & Rasa positif & 7,8 & 2 & & \\
\hline & Kesamaan & 9,10 & 2 & & \\
\hline & & & & & \\
\hline Jumlah & & & 10 & & \\
\hline
\end{tabular}

\section{d. Indikator Kinerja ( $Y$ )}

Adapun indikator kinerja pegawai adalah sebagai berikut (Wahyudi, 2015):

1. Kuantitas

2. Kualitas

3. Tanggungjawab

4. Efektifitas

5. Kerjasama

6. Ketaatan

Tabel 4

Kisi-Kisi Instrumen Kinerja 


\begin{tabular}{|c|c|c|c|c|c|}
\hline Definisi & Indikator & $\begin{array}{c}\text { No } \\
\text { Butir }\end{array}$ & Jumlah & Instrumen & $\begin{array}{c}\text { Skala } \\
\text { pengukuran }\end{array}$ \\
\hline \multirow{6}{*}{$\begin{array}{l}\text { Menurut Wahyudi } \\
\text { "kinerja merupakan } \\
\text { salah satu alat ukur bagi } \\
\text { pencapaian organisasi. } \\
\text { kinerja dapat dipandang } \\
\text { sebagai 'thing done'. } \\
\text { Kinerja sebagai hasil } \\
\text { kerja secara kualitas } \\
\text { dan kuantitas yang } \\
\text { dicapai oleh seorang } \\
\text { pegawai dalam } \\
\text { melaksanakan tugasnya } \\
\text { sesssuai dengan } \\
\text { tanggung jawab yang } \\
\text { diberikan kepadanya" }\end{array}$} & Kualitas & 1,2 & 2 & \multirow{6}{*}{$\begin{array}{l}\text { Kuesioner } \\
\text { Skala Likert } \\
\text { Instrumen 1- } \\
5\end{array}$} & \multirow[t]{6}{*}{ Interval } \\
\hline & Kuantitas & 3,4 & 2 & & \\
\hline & $\begin{array}{c}\text { Tanggung } \\
\text { jawab }\end{array}$ & 5,6 & 2 & & \\
\hline & Efektivitas & 7,8 & 2 & & \\
\hline & Kerja sama & 9,10 & 2 & & \\
\hline & Ketaatan & 11,12 & 2 & & \\
\hline Jumlah & & & 12 & & \\
\hline
\end{tabular}

\section{e. Uji Validitas dan Reliabilitas}

Uji Validitas dan realibilitas diperlukan sebelum angket disebar ke responden. merupakan derajad ketetapan antara data yang terjadi pada obyek penelitian dengan daya yang dapat dilaporkan oleh peneliti. Dengan demikian data yang valid adalah data "yang tidak berbeda" antara data yang dilaporkan oleh peneliti dengan data yang sesungguhnya terjadi pada obyek penelitian (Sugiyono, 2017).

Instrument yang valid berarti alat ukur yang digunakan untuk mendapatkan data (mengukur) itu valid. Uji validitas digunakan untuk mendapatkan tingkat kevalidan dan kesahihan suatu instrument. Perhitungan uji validitas ini menggunakan bantuan Statistical Package for the Social Science (SPSS) 26 (Basuki, 2014). Pengujian validitas ini dilakukan menggunakan rumus Product Moment sebagai berikut :

$$
\operatorname{Rxy}=\frac{\mathrm{n}\left(\sum \mathrm{XY}\right)-\left(\sum \mathrm{X}\right)\left(\sum \mathrm{Y}\right)}{\sqrt{\mathrm{n} \cdot \sum \mathrm{X}^{2}-\left(\sum \mathrm{X}^{2}\right)\left(\mathrm{n} \cdot \sum \mathrm{Y}^{2}-\left(\sum \mathrm{Y}^{2}\right)\right.}}
$$

Keterangan :

$\mathrm{r}_{\mathrm{xy}}=$ Besar korelasi Product moment dari setiap pertanyaan

$\mathrm{n} \quad=$ Jumlah Responden

$\sum_{\mathrm{x}^{2}}=$ Jumlah Kuadrat $\mathrm{x}$

$\sum_{\mathrm{y}^{2}}=$ Jumlah Kuadrat y

$\mathrm{x}=$ Skor Pernyataan

$\mathrm{y}=$ Skor Semua Pernyataan Dari Satu Responden

Sedangkan untuk mengetahui skor masing-masing item pertanyaan valid atau tidak, maka ditetapkan criteria statistic sebagai berikut :

a) Jika $r$ hitung $>\mathrm{r}$ tabel, maka variabel tersebut valid 
Prosiding The 1st National Conference on Applied Business, Education, \& Technology (NCABET)"

Unversitas Bina Bangsa 2021

DOI Article : 10.46306/ncabet.v1i1.16

b) Jika $r$ hitung < r tabel, maka variabel tersebut tidak valid

c) Jika $r$ hitung $<$ r tabel maka H0 akan tetap ditolak dan H1 diterima.

d) Uji Coba Instrumen

\section{f. Teknik analisis Data}

Dalam rangka menganalisis data penelitian dipergunakan statistic deskriptif dan statistik inferensial. Statistik deskriptif dipilih dan dipergunakan dengan maksud untuk menggambarkan karakteristik penyebaran skor setiap variabel. Sedangkan statistik inferensial dalam penelitian ini dipergunakan untuk mengetahui pengaruh variabel komunikasi interpersonal (X) terhadap kinerja pegawai (Y) dengan

menggunakan analisis regresi linear.

\section{g. Analisis Regresi Linear}

Analisis regresi linear berganda digunakan untuk mengetahui arah hubungan antara variabel independen dengan variabel dependen apakah masing-masing variabel independen berhubungan postif atau negative dan untuk memprediksi nilai dari suatu variabel dependen apabila nilai variabel independen mengalami kenaikan atau penurunan. Menyatakan seberapa besar pengaruh naik turunnya nilai variabel terikat terhadap dua atau lebih variabel bebas. Berdsarkan hasil analisis regresi yang menunjukan besarnya pengaruh masing-masing variabel independen yaitu komunikasi interpersonal (X) terhadap variabel dependen yaitu kinerja pegawai (Y) Kantor Kecamatan Jawilan Kabupaten Serang.

$$
\mathbf{Y}=\mathbf{a}+\boldsymbol{b} \mathbf{x}+\mathbf{e}
$$

Keterangan :

Y : Variabel Kinerja Pegawai (Variabel terikat)

$\mathrm{X}$ : Variabel Komunikasi interpersonal (Variabel bebas)

a : Konstanta

b : Koefisien Regresi

e : Standar erro of the estimate

\section{h. Analisis Koefisien Korelasi}

Analisis ini digunakan untuk mengetahui derajat hubungan antara variabel Komunikasi Interpersonal (X) dengan variabel Kinerja pegawai (Y). kriteria yang digunakan untuk menentukan tinggi rendahnya hubungan yang terjadi anatara variabel adalah :

Tabel 5

Koefisien Korelasi

\begin{tabular}{|c|c|}
\hline Interval Koefisien & Tingkat hubungan \\
\hline $0,00-0,199$ & Sangat rendah \\
\hline $0,20-0,399$ & Rendah \\
\hline
\end{tabular}




\begin{tabular}{|c|c|}
\hline $0,40-0,599$ & Sedang \\
\hline $0,60-0,799$ & Kuat \\
\hline $0,80-01,000$ & Sangat kuat \\
\hline
\end{tabular}

Sumber : (Sugiyono, 2015)

\section{i. Analisis Koefisien Determinasi}

Uji koefisien determinasi digunankan untuk mengetahui seberapa besarnya pengaruh variabel bebas terhadap variabel terikat, dengan kata lain untuk mengukur seberapa presentase (\%) pengaruh variabel bebas yang diteliti yaitu komunikasi interpersonal (X) terhadap kinerja pegawai (Y) dengan rumus sebagai berikut:

$$
\mathrm{KD}=\mathrm{R}^{2} \times 100 \%
$$

Dimana :

KD $\quad$ : Koefisien determinasi

R : Koefisien korelasi

\section{j. Uji Hipotesis}

\section{1) Uji T (parsial)}

Uji T bertujuan untuk mengetahui pengaruh variabel independen yaitu motivasi kerja dan komunikasi interpersonal secara parsial terhadap variabel dependen yaitu kinerja pegawai Kantor Kecamatan Jawilan Kabupaten Serang. Uji T atau uji hipotesis dapat dilakukan dengan rumus sebagai berikut :

$$
\mathrm{DF}=\alpha / 2:(\mathrm{N}-1-\mathrm{K})
$$

Suatu koefisien korelasi harus mempunyai nilai yang berarti (signifikan) untuk menguji kebenaran koefisien korelasi langkah-langkah yang ditempuh sebagai berikut :

a) Kriteria pengujian hipotesis

a. Menguji komunikasi interpersonal terhadap kinerja pegawai

$\mathrm{H}_{0}=0$, artinya komunikasi interpersonal tidak berpengaruh terhadap kinerja pegawai.

$\mathrm{H}_{0}>0$, artinya komunikasi interpersonal berpengaruh terhadap kinerja pegawai.

b) Menentukan taraf nyata

Taraf nyata yang digunakan adalah $5 \%$ atau 0,05 kriteria pengembilan keputusan uji parsial adalah :

a. Jika $t_{\text {hitung }}<t_{\text {tabel }}$, maka $\mathrm{H}_{0}$ ditolak dan $\mathrm{H}_{\mathrm{a}}$ ditolak, artinya tidak terdapat pengaruh yang signifikan anatara komunikasi interpersonal (X) terhadap kinerja pegawai (Y).

b. Jika $t_{\text {hitung }}>t_{\text {tabel }}$, maka $\mathrm{H}_{0}$ ditolak dan $\mathrm{H}_{\mathrm{a}}$ diterima, artinya terdapat pengaruh yang signifikan antara komunikasi interpersonal (X) terhadap kinerja pegawai (Y). 
Prosiding The 1st National Conference on Applied Business, Education, \& Technology (NCABET)"

Unversitas Bina Bangsa 2021

DOI Article : 10.46306/ncabet.v1i1.16

Uji $t$ dapat juga dilakukan dengan melihat nilai signifikan $t$ masing-masing variabel yang terdapat pada output hasil regresi menggunakan SPSS . Jika angka signifikan $\mathrm{t}<\alpha(0.05)$ maka dapat dikatakan bahwa terdapat pengaruh yang kuat Antara variabel independen dengan variabel dependen (Sugiyono, 2015).

\section{k. Hipotesis Statistika}

Hipotesis merupakan jawaban sementara terhadap rumusan masalah penelitian, dimana rumusan masalah penelitian telah dinyatakan dengan kalimat pernyataan.

Uji hipotesis berguna untuk menguji keberpengaruhan antara variabel sehingga terbukti bahwa kedua variabel tersebut memiliki keeratan hubungan yang signifikan atau sebaliknya. Untuk mengetahui hal ini maka dilakukan uji hipotesis, pada penelitian ini digunakan uji parsial $(\mathrm{X} \rightarrow \mathrm{Y})$.

- $\mathrm{H}_{0}=0$ artinya tidak terdapat pengaruh komunikasi interpersonal terhadap kinerja pegawai.

- $\mathrm{H}_{0}>0$, artinya komunikasi interpersonal berpengaruh terhadap kinerja pegawai.

\section{HASIL DAN PEMBAHASAN}

Sebagai contoh karakteristik kehidupan sosial mewajibkan setiap individu untuk membangun sebuah relasi dengan yang lain, sehingga akan terjalin sebuah ikatan perasaan yang bersifat timbal balik dalam suatu pola hubungan yang dinamakan hubungan interpersonal (Benny Usman, 2013). Komunikasi interpersonal, atau biasaa disebut komunikasi antar pribadi, adalah komunikasi antara individu-individu (Nashrudin P., 2011). Begitupun Mulyana ( M u ly a na, 2010 ) menyatakan bahwa, "komunikasi interpersonal atau komunikasi interpersonaladalah komunikasi antara orang-orang secara tatap muka, yang memungkinkan setiap pesertanya menangkap reaksi orang lain secara langsung, baik secara verbal maupun non verbal".

Hal yang sama juga diperkuat oleh pernyataan Devito (dalam Effendy, 2003) menyatakan bahwa, "Komunikasi interpersonal adalah penyampaian pesan oleh satu orang dan penerimaan pesan oleh orang lain atau sekelompok kecil orang, dengan berbagai dampaknya dan dengan peluang untuk memberikan umpan balik segera”. Kemudian, faktor pembentuk variabel komunikasi interpersonal dalam penelitian terdiri dari lima indikator variabel yaitu: 1) keterbukaan (openess, ) 2) Empati (emphaty) 3) Dukungan (supportiveness) 4) rasa positif (positiveness) dan 5) kesetaraan (equality) di adopsi dari teori Agus M. Hardjana (Agus M. Hardjana, 2003); (Mulyana, 2010), (Muhammad, 2014); (Effendy. Onong Uchjana, 2011); (Faidha, 2020). Selanjutnya penelitian ini berusaha mengartikulasi, menguji dan menganalisis komunikasi interpersonal yang dilakukan oleh (Femin, 2014) dengan hasil penelitian menunjukkan bahwa komunikasi interpersonal berpengaruh signifikan terhadap kinerja. 
Sedangkan definisi kinerja disebutkan oleh Robbins yaitu suatu hasil yang dicapai oleh pegawai dalam pekerjaannya menurut kriteria tertentu yang berlaku untuk suatu pekerjaan. Kinerja adalah tingkatan pencapaian hasil atas pelaksanaan tugas tertentu. (Simanjuntak, 2005). Mathis dan Jackson (Mathis, Robert L dan Jackson, 2004) menyebutkan tentnag Kinerja (Perfomance AppraisalPA) adalah proses evaluasi seberapa baik karyawan mengerjakan pekerjaan dibandingkan dengan satu set standar, dan kemudian mengkomunikasikannya dengan para karyawan.

Kinerja adalah kemampuan pegawai menyelesaikan kewajibannya sesuai dengan waktu dan rencana atau sesuai dengan yang diharapkan. Pengukuran kinerja karyawan dapat dilakukan terhadap kinerja yang nyata dan terukur Abdullah (Abdullah, 2014). Faktor pembentuk variabel kinerja pegawai dalam penelitian ini yang dikemukakan oleh (Edy, 2018) yang terdiri dari 1) kuantitas kerja, 2) kualitas kerja, 3) ketangguhan, 4) kerja sama dan 5) ketepatan waktu.

Komunikasi interpersonal dalam aktifitas pelayanan di Kecamatan Jawilan Kabupaten Serang, biasanya dilakukan dalam bentuk koordinasi antara atasan dengan bawahan, atau antar pegawai. Fenomena yang terjadi dalam aktifitas pelayanan publik sebagaimana definisi nya yaitu "kegiatan atau rangkaian kegiatan dalam rangka pemenuhan kebutuhan pelayanan sesuai dengan peraturan perundangundangan bagi setiap warga negara dan penduduk atas barang, jasa, dan/atau pelayanan administratif yang disediakan oleh penyelenggara pelayanan publik “(UU No. 25 Tahun 2009, pasal 1). Pelayanan publik dijalankan berdasarkan asas: a) kepentingan umum; b) kepastian hukum; c) kesamaan hak; d) keseimbangan hak dan kewajiban; e) keprofesionalan; f) partisipatif; g) persamaan perlakuan/tidak diskriminatif; h) keterbukaan; i) akuntabilitas; j) fasilitas dan perlakuan khusus bagi kelompok rentan; k) ketepatan waktu; dan 1) kecepatan, kemudahan, dan keterjangkauan (UU No. 25 tahun 2009 pasal 4).

Komunikasi interpersonal berpengaruh positif dan signifikan terhadap kinerja pegawai yang dilakukan oleh Pegawai Kecamatan Jawilan Kabupaten Serang. Hal ini dibuktikan dengan jawaban responden secara keseluruhan tentang komunikasi interpersonal menyatakan sudah sangat baik dengan nilai rata-rata 4,59. Artinya bahwa mayoritas responden menyatakan secara keseluruhan mengenai penerapan komunikasi interpersonal meliputi: keterbukaan, empati, dukungan dan rasa positif sudah sangat baik. Kemudian berdasarkan hasil uji parsial analisis regresi komunikasi interpersonal $(\mathrm{X})$ berpengaruh signifikan terhadap kinerja pegawai (Y). Hal ini sesuai dengan kondisi di lapangan menunjukkan bahwa komunikasi dinilai sebagai aspek yang penting ketika melakukan pelayanan publik, komunikasi adalah proses penyampaian pesan yang dilakukan oleh komunikator (pegawai) kepada masyarakat (komunikan) atau antar pegawai Kecamatan Jawilan, baik tentnagn maalah pekerjaan (koordinasi) maupun komunikasi lain dalam rangka melaksanakan tugas. 
Prosiding The 1st National Conference on Applied Business, Education, \& Technology (NCABET)"

Unversitas Bina Bangsa 2021

DOI Article : 10.46306/ncabet.v1i1.16

Komunikasi interpersonal merupakan suatu proses komunikasi yang paling efektif, Karena para pegawai komunikasi dapat terus menerus saling menyesuaikan diri. Dengan adanya hubungan komunikasi interpersonal maka hubungan yang terjalin akan semakin harmonis dikarenakan adanya sikap saling memahami, sehingga akan memunculkan rasa nyaman dan mampu meningkatkan kinerja. Temuan ini sesuai dengan teori yang yang diungkapkan oleh Efendi (Effendy. Onong Uchjana, 2011) mendifinisikan komunikasi sebagai proses penyampaian pesan oleh seseorang kepada orang lain untuk memberitahu, mengubah sikap, pendapat, atau perilaku, baik secara lisan (langsung) ataupun tidak langsung (melalui media). Sopiah (2008) komunikasi didefinisikan sebagai penyampaian atau pertukaran informasi dari pengirim kepada penerima baik secara lisan, tertulis, maupun menggunakan alat komunikasi. Baharum et al (2005) mendefinisikan bahwa komunikasi adalah aspek dan elemen yang penting dalam kefungsian sebuah organisasi.

Carl I. Hovland (Effendy. Onong Uchjana, 2011) mendefinisikan bahwa komunikasi adalah proses yang memungkinkan seseorang (komunikator) menyampaikan rangsangan untuk mengubah perilaku orang lain (komunikan). Nashrudin. Komunikasi dapat juga meliputi pertukaran informasi antara manusia dan mesin. Komunikasi merupakan suatu proses yang vital dalam organisasi karena komunikasi diperlukan bagi efektivitas kepemimpinan, perencanaan, pengendalian, koordinasi, latihan, manajemen konflik, serta proses- proses organisasi lainnya. Hal ini sesuai dengan variabel penelitian komunikasi interpersonal berpengaruh positif dan signifikan yang dilakukan oleh, Festus Femin (Femin, 2014).

\section{A. Deskripsi Data}

\section{Karakteristik Data Responden di Kantor Kecamatan Jawilan}

Responden dalam penelitian ini adalah seluruh pegawai di kantor Kecamatan Jawilan kabupaten serang sebanyak 40 orang. Di bawah ini karakteristik responden yang terlibat dalam penelitian yang dilakukan berdasarkan jenis kelamin dan pendidikan terakhir.

\section{Tabel 6}

Responden Berdasarkan Jenis Kelamin

\begin{tabular}{|l|l|c|c|}
\hline No & Keterangan & Frekuensi & Presentase\% \\
\hline 1. & Laki-Laki & 32 & $80 \%$ \\
\hline 2. & Perempuan & 8 & $20 \%$ \\
\hline \multicolumn{2}{|l|}{ Jumlah } & 40 & $100 \%$ \\
\hline
\end{tabular}

Sumber : Data Primer Diolah

Berdasarkan tabel diatas dapat disimpulkan bahwa jumlah responden pada saat dilaksanakan survey, jumlah laki-laki sebanyak $80 \%$ dan jumlah perempuan sebanyak $20 \%$.

\section{Tabel 7}

Responden Berdasarkan Pendidikan Terakhir

\begin{tabular}{|l|c|c|c|}
\hline No & Keterangan & Frekuensi & Presentase $\%$ \\
\hline
\end{tabular}




\begin{tabular}{|c|c|c|c|}
\hline 1. & SMA/Sederajat & 21 & $53 \%$ \\
\hline 2. & Diploma & 3 & $8 \%$ \\
\hline 3. & Sarjana (S1) & 10 & $25 \%$ \\
\hline 4. & Pasca Sarjana (S2) & 6 & $15 \%$ \\
\hline & Jumlah & 40 & $100 \%$ \\
\hline
\end{tabular}

\section{Sumber : Data Primer Diolah}

Berdasarkan tabel diatas dapat disimpulkan bahwa jumlah responden pada saat dilakukan survey, jumlah pegawai yang berpendikan terakhir SMA/Sederajat berjumlah 53\%, pegawai yang berpendidikan Diploma berjumlah 8\%, pegawai yang berpendidikan terakhir Sarjana (S1) berjumlah 25\% dan pegawai yang berpendidikan Pasca Sarjana (S2) berjumlah $15 \%$.

\section{B. Uji Validitas dan Reliabilitas Variabel Kinerja Pegawai}

\section{1) Uji Validitas Variabel Kinerja Pegawai}

Berdasarkan analisis uji validitas variabel kinerja pegawai, berikut ini adalah hasil perhitungan statistik deskriptif yang didapat dari jawaban responden melalui kuesioner untuk variabel kinerja pegawai ditampilkan pada tabel sebagai berikut :

Tabel 8

Output Uji Validitas Variabel Kinerja Pegawai

\begin{tabular}{|c|c|c|c|c|}
\hline \multicolumn{5}{|c|}{ Item-Total Statistics } \\
\hline & $\begin{array}{c}\text { Scale Mean if } \\
\text { Item Deleted }\end{array}$ & $\begin{array}{c}\text { Scale Variance } \\
\text { if Item Deleted }\end{array}$ & $\begin{array}{c}\text { Corrected Item- } \\
\text { Total } \\
\text { Correlation }\end{array}$ & $\begin{array}{c}\text { Cronbach's Alpha } \\
\text { if Item Deleted }\end{array}$ \\
\hline Y1 & 46.38 & 24.651 & $\mathbf{. 5 2 2}$ & .825 \\
\hline Y2 & 45.83 & 26.507 & $\mathbf{. 4 4 9}$ & .832 \\
\hline Y3 & 45.95 & 23.587 & $\mathbf{. 6 9 5}$ & .812 \\
\hline Y4 & 45.95 & 25.228 & $\mathbf{. 5 5 7}$ & .824 \\
\hline Y5 & 47.20 & 23.087 & $\mathbf{. 5 4 9}$ & .823 \\
\hline Y6 & 47.03 & 24.487 &. $\mathbf{4 2 3}$ & .834 \\
\hline Y7 & 46.25 & 25.064 & $\mathbf{. 3 3 9}$ & .842 \\
\hline Y8 & 46.23 & 24.435 & $\mathbf{. 5 6 2}$ & .822 \\
\hline Y9 & 46.35 & 23.874 & $\mathbf{. 5 3 4}$ & .824 \\
\hline Y10 & 46.03 & 24.743 & $\mathbf{. 7 0 3}$ & .816 \\
\hline Y11 & 46.28 & 24.974 & $\mathbf{. 3 9 2}$ & .836 \\
\hline Y12 & 46.05 & 25.279 & $\mathbf{. 5 0 4}$ & .827 \\
\hline
\end{tabular}

Sumber : Hasil Pengolahan SPSS

Dari hasil outuput diatas bahwa semua indikator yang ada di variabel kinerja pegawai dinyatakan valid karena nilai $r$ hitung lebih besar dari $r$ tabel. Dimana untuk $r$ tabelnya adalah 0.312 .

\section{2) Uji Reliabilitas Kinerja Pegawai}


Prosiding The 1st National Conference on Applied Business, Education, \& Technology (NCABET)"

Unversitas Bina Bangsa 2021

DOI Article : 10.46306/ncabet.v1i1.16

Berdasarkan analisis uji reliabilitas variabel kinerja pegawai, berikut ini adalah hasil perhitungan yang ditampilkan pada tabel sebagai berikut :

Tabel 9

Output Uji Reliabilitas Kinerja pegawai

\begin{tabular}{|l|l|}
\hline \multicolumn{2}{|l|}{ Reliability Statistics } \\
\hline Cronbach's Alpha & N of Items \\
\hline .839 & 12 \\
\hline
\end{tabular}

Dari tabel di atas hasil yang diperoleh melalui analisa yang ditunjukan dengan nilai alpha cronbach 0,839 atau lebih besar dari 0,6 maka kinerja pegawai dinyatakan reliabel.

\section{Uji Validitas dan Reliabilitas Komunikasi Interpersonal}

1) Uji validitas Komunikasi Interpersonal

Berdasarkan analisis uji validitas variabel komunikasi interpersonal, berikut ini adalah hasil perhitungan statistik deskriptif yang didapat dari jawaban responden melalui kuesioner untuk variabel komunikasi interpersonal ditampilkan pada tabel sebagai berikut:

Tabel 10

\section{Output Uji Validitas Variabel Komunikasi Interpersonal}

\begin{tabular}{|c|c|c|c|c|}
\hline \multicolumn{2}{|l|}{ Item-Total Statistics } \\
\hline & $\begin{array}{l}\text { Scale Mean if } \\
\text { Item Deleted }\end{array}$ & $\begin{array}{l}\text { Scale Variance } \\
\text { if Item Deleted }\end{array}$ & $\begin{array}{l}\text { Corrected Item- } \\
\text { Total } \\
\text { Correlation }\end{array}$ & $\begin{array}{l}\text { Cronbach's } \\
\text { Alpha if Item } \\
\text { Deleted }\end{array}$ \\
\hline X.1 & 38.78 & 21.769 & $\mathbf{. 5 8 8}$ & .882 \\
\hline X.2 & 38.88 & 20.984 & $\mathbf{. 7 0 7}$ & .874 \\
\hline X.3 & 38.70 & 22.062 & $\mathbf{. 6 6 2}$ & .878 \\
\hline X.4 & 39.07 & 20.328 & $\mathbf{. 6 2 6}$ & .881 \\
\hline X.5 & 38.90 & 20.964 & $\mathbf{. 7 2 1}$ & .873 \\
\hline X.6 & 39.05 & 21.741 & $\mathbf{. 4 9 4}$ & .890 \\
\hline X.7 & 38.55 & 22.459 & $\mathbf{. 5 0 6}$ & .888 \\
\hline X.8 & 38.60 & 21.938 & $\mathbf{. 6 3 3}$ & .880 \\
\hline X.9 & 39.00 & 21.077 & $\mathbf{. 6 6 8}$ & .877 \\
\hline X.10 & 38.82 & 20.917 & $\mathbf{. 7 4 6}$ & .872 \\
\hline
\end{tabular}

Sumber : Hasil pengolahan SPSS

Dari hasil outuput diatas bahwa semua indikator yang ada di variabel komunikasi interpersonal dinyatakan valid karena nilai $r$ hitung lebih besar dari $r$ tabel. Dimana untuk $r$ tabelnya adalah 0,312 .

2) Uji Reliabilitas Komunikasi Interpersonal 
Berdasarkan analisis uji reliabilitas variabel motivasi kerja, berikut ini adalah hasil perhitungan yang ditampilkan pada tabel sebagai berikut :

Tabel 11

Output Uji Reliabilitas Komunikasi Interpersonal
\begin{tabular}{|l|l|}
\hline Reliability Statistics \\
\hline Cronbach's Alpha & N of Items \\
\hline .890 & 10 \\
\hline
\end{tabular}

Dari tabel di atas hasil yang diperoleh melalui analisa yang ditunjukan dengan nilai alpha cronbach 0,890 atau lebih besar dari 0,6 maka komunikasi interpersonal dinyatakan reliabel.

\section{Uji Regresi Linier Sederhana}

Analisis ini dimaksudkan untuk mengetahui pengaruh variabel Komunikasi Inyerpersonal terhadap Kinerja karyawan. Dan hasil pengolahan data dengan bantuan software SPSS Versi 26 dapat dilihat pada tabel sebagai berikut :

Tabel 12

Output Uji Regresi Linear

\begin{tabular}{|c|c|c|c|c|c|c|}
\hline \multicolumn{7}{|c|}{ Coefficients $^{\mathrm{a}}$} \\
\hline \multirow{2}{*}{\multicolumn{2}{|c|}{ Model }} & \multicolumn{2}{|c|}{$\begin{array}{l}\text { Unstandardized } \\
\text { Coefficients }\end{array}$} & \multirow{2}{*}{$\begin{array}{l}\text { Standardized } \\
\text { Coefficients } \\
\text { Beta }\end{array}$} & \multirow{2}{*}{$t$} & \multirow{2}{*}{ Sig. } \\
\hline & & B & Std Eror & & & \\
\hline 1 & (Constant) & 6.929 & 4.353 & & 1.592 & 0.120 \\
\hline & Komunikasi Interpersonal & 0.686 & 0.115 & 0.652 & 5.983 & 0.000 \\
\hline
\end{tabular}

Dari hasil pengolahan di atas dengan bantuan software SPSS Versi 26 disusun persamaan sebagai berikut :

$$
\begin{aligned}
& Y=a+b X \\
& Y=6.929+0.652 X
\end{aligned}
$$

Interpretasi Persamaan Regresi

1. Jika Variabel Komunikasi Interpersonal nol, maka Kinerja pegawai sebesar 6.929 satuan.

2. Jika Komunikasi interpersonal naik satu satuan maka Kinerja pegawai naik sebesar 0.686 satuan.

\section{E. Uji Koefisien Korelasi (R)}

Koefisien korelasi adalah alat uji yang digunakan untuk menguji hipotesis asosiatif (uji hubungan) dua variabel bila datanya berskala interval atau rasio, untuk menguji korelasi digunakan teknik uji korelasi product moment (korelasi pearson) yang dikembangkan oleh Karl 
Prosiding The 1st National Conference on Applied Business, Education, \& Technology (NCABET)"

Unversitas Bina Bangsa 2021

DOI Article : 10.46306/ncabet.v1i1.16

Pearson. Berikut adalah hasil pengolahan data dengan bantuan software SPSS Versi 26 dapat dilihat pada tabel berikut :

Tabel 13

Hasil Uji Koefisien Korelasi

\begin{tabular}{|l|l|l|l|l|}
\hline \multicolumn{3}{|l|}{ Model Summary ${ }^{\boldsymbol{b}}$} \\
\hline Model & $R$ & $\begin{array}{l}\text { Square } \\
\text { Sqjusted } \\
\text { Square } \\
\text { Std. Error of } \\
\text { the Estimate }\end{array}$ \\
\hline 1 & $.864^{\mathrm{a}}$ & $\mathbf{0 . 7 4 6}$ & 0.733 & 2.781 \\
\hline \multicolumn{3}{|l|}{ Predictors: (Constant), Komunikasi Interpersonal } \\
\hline \multicolumn{2}{|l}{ b. Dependent Variabel: Kinerja Pegawai } \\
\hline
\end{tabular}

Berdasarkan output SPSS di atas, dapat diketahui besarnya koefisien korelasi adalah sebesar 0,864 maka kualitas hubungan antara komunikasi dengan Kinerja berada pada kategori sangat kuat.

\section{F. Koefisien Determinasi $\left(\mathbf{R}^{2}\right)$}

Koefisien determinasi $\left(\mathrm{R}^{2}\right)$ digunakan sebagai alat ukur besarnya kontribusi variabel bebas terhadap variabel terikat.

Berdasarkan tabel 13, dapat diketahui bahwa nilai nilai koefisien determinasi (R2) sebesar 0,746. Selanjutnya digunakan perhitungan koefisien determinasi (KD) untuk mengetahui besarnya pengaruh variabel motivasi kerja dan komunikasi interpersonal terhadap kinerja pegawai.

$$
\begin{aligned}
K D & =\left(R^{2}\right) \times 100 \% \\
\left(R^{2}\right) & =0,746 \times 100 \% \\
& =74,6 \%
\end{aligned}
$$

Hal ini dapat disimpulkan bahwa Komunikasi interpersonal (X) memberikan kontribusi sebesar 74,6\% terhadap Kinerja pegawai (Y) sedangkan 25,4\% dipengaruhi variabel lain yang tidak dibahas dalam penelitian ini.

\section{G. Pengujian Hipotesis}

Pengujian hipotesis dalam penelitian ini menggunakan persamaan regresi linier berganda dan melakukan perhitungan menggunakan software SPSS Versi 26. Analisis ini dimaksudkan untuk mengetahui apakah variabel bebas independent berpengaruh atau tidak terhadap variabel terikat dependent.

1. Uji Signifikansi Parameter Secara Parsial (Uji T)

Uji t dikenal dengan uji parsial, yaitu untuk menguji bagaimana pengaruh masing-masing variabel bebasnya secara sendiri-sendiri terhadap variabel terikatnya. Untuk menguji apakah 
hipotesis yang ditetapkan semula diterima atau ditolak, maka dilakukan perbandingan nilai t hitung dengan t tabel. Dalam uji ini peneliti menggunakan bantuan software SPSS Versi 26. Untuk mengetahui nilai dengan kriteria pengujian sebagai berikut :

- $\quad$ Jika $t_{\text {hitung }}>t_{\text {tabel }}$, maka Ho ditolak dan Ha diterima.

- $\quad$ Jika $t_{\text {hitung }}<\mathrm{t}_{\text {tabel }}$, maka Ho diterima dan Ha ditolak.

Berdasarkan analisis uji T (parsial) dengan software SPSS Versi 26, berikut ini adalah hasil perhitungan yang ditampilkan pada tabel berikut :

Tabel 14

Hasil Uji T

\begin{tabular}{|c|c|c|c|c|c|c|}
\hline \multicolumn{7}{|c|}{ Coefficients $^{a}$} \\
\hline & \multirow{2}{*}{ Model } & \multicolumn{2}{|c|}{$\begin{array}{c}\text { Unstandardized } \\
\text { Coefficients }\end{array}$} & \multirow{2}{*}{$\begin{array}{c}\text { Standardized } \\
\text { Coefficients }\end{array}$} & \multirow[t]{2}{*}{$t$} & \multirow[t]{2}{*}{ Sig. } \\
\hline & & $B$ & Std Eror & & & \\
\hline \multirow[t]{2}{*}{1} & (Constant) & 6.929 & 4.353 & & 1.592 & 0.120 \\
\hline & $\begin{array}{l}\text { Komunikasi } \\
\text { Interpersonal }\end{array}$ & 0.686 & 0.115 & 0.652 & 5.983 & 0.000 \\
\hline
\end{tabular}

Dengan menggunakan tes uji 2 arah dan tingkat signifikansi sebesar $=5 \%$ atau 0,05 dengan derajat kebebasan (df) N-K-1 = 40-2-1 = 37 maka diperoleh nilai sebesar 2.026.

Berdasarka Hipotesis yang diajukan, maka :

Ho : secara parsial tidak ada pengaruh antara komunikasi interpersonal terhadap Kinerja pegawai Ha : secara parsial ada pengaruh antara komunikasi interpersonal terhadap Kinerja pegawai

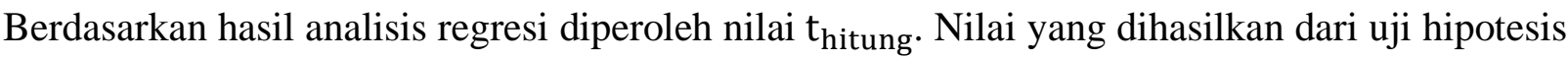
untuk $t_{\text {hitung }}$ komunikasi interpersonal sebesar 5,983. Diketahui nilai $t_{\text {tabel }}$ sebesar 2,026, karena nilai $t_{\text {hitung }}$ lebih besar dari $t_{\text {tabel }}$ ( $t_{\text {hitung }} 5,983>t_{\text {tabel }} 2,026$ ), maka Ho ditolak dan Ha diterima. Hal ini membuktikan bahwa ada pengaruh antara komunikasi interpersonal terhadap Kinerja pegawai.

\section{KESIMPULAN}

Berdasarkan hasil penelitian dan pembahasan dapat ditarik kesimpulan sesuai dengan rumusan masalah adalah sebagai berikut:

1. Hasil penelitian ini menunjukkan bahwa terdapat pengaruh positif antara komunikasi interpersonal dengan kinerja pegawai.menunjukkan nilai (thitung 5,983 > ttabel 2,024), maka Ho ditolak dan 
Prosiding The 1st National Conference on Applied Business, Education, \& Technology (NCABET)"

Unversitas Bina Bangsa 2021

DOI Article : 10.46306/ncabet.v1i1.16

Ha diterima. Berarti bahwa Komunikasi Interpersonal berpengaruh signifikan terhadap kinerja pegawai Kecamatan Jawilan. Maka dapat disimpulkan hipotesis.

2. Hasil koefisien korelasi sederhana $(\mathrm{R}$ ) adalah $=\mathbf{0 , 7 4 6}$, maka dapat disimpulkan bahwa ada hubungan ynag sangat kuat antara Komunikasi Interpersonal dengan Kinerja Pegawai pada Kantor Keamatan Jawilan,, Kabupaten Serang.

3. Berdasarkan hasil analisis regersi dapat diketahui bahwa terdapat pengaruh posited antarar variabel Komunikasi Interpersonal (X) dan variabel Kinerja Pegawai (Y) pada Kantor Kecamatan Jawitan, Kabupaten Serang. Hal ini dapat ditunjukkan darai persamaann regresi $\mathbf{Y}=\mathbf{6 . 9 2 9}+$ $0.652 X$

\section{UCAPAN TERIMAKASIH}

Beberapa pihak yang telah membantu dan memberikan dukungan dalam penyusunan artikel ini, penulis menyampaikan terima kasih dan penghargaan yang setinggi-tingginya, khusus kepada $\mathrm{H}$. Agus Saepudin, SE, M.Si Camat Jawilan dan Adang Hadi, S.Sos. Plt. Sekretaris Camat Jawilan yang telah banyak membantu dalam menyusun artikel

\section{DAFTAR PUSTAKA}

Abdullah, M. (2014). Manajemen dan Evaluasi Kinerja Karyawan. Penerbit Aswaja Pressindo. Agus M. Hardjana. (2003). Komunikasi intrapersonal \& Komunikasi Intrpersonal. Kanisius. Basuki, T. A. (2014). Penggunaan SPSS Dalam Statistik. Danisa Media.

Benny Usman. (2013). Pengaruh Komunikasi Interpersonal Terhadap Kinerja Pegawai Pada Fakultas Ekonomi Universitas PGRI Palembang. Jurnal Media Wahana Ekonomika, Vol. 10, No.1, April 2013: $\quad 1 \quad-18, \quad 10(1), \quad 1-18 . \quad$ https://jurnal.univpgripalembang.ac.id/index.php/Ekonomika/article/view/2754/2552

Edy, S. (2018). Manajemen Sumber Daya Manusia. Kencana.

Effendy. Onong Uchjana. (2011). Ilmu Komunikasi Teori dan Praktek. PT. Remaja Rosdakarya.

Faidha, F. (2020). Pengaruh Komunikasi Interpersonal Terhadap Kinerja Penyuluh Keluarga Berencana (Pkb) Di Bkkbn Propinsi Sulawesi Tenggara. Kybernan: Jurnal Studi Kepemerintahan, 3(1), 23-39. https://doi.org/10.35326/kybernan.v1i1.581

Femin, F. (2014). The Impact of Communication on Workers' Performance in Selected Organisations in Lagos State: Nigeria.

Mathis, Robert L dan Jackson, J. H. (2004). Manajemen Sumber Daya Manusia. Salemba Empat.

Muhammad, A. (2014). Komunikasi Organisasi. PT. Bumi Aksara.

Mulyana, D. (2010). Pengantar Ilmu Komunikasi. Remaja Rosdakarya.

Nashrudin P., A. (2011). Kapita Selekta Ilmu Komunikasi. Dinas Pendidikan dan Kebudayaan Banten.

Simanjuntak. (2005). Manajemen Dan Evaluasi Kinerja. Fakultas Ekonomi Universitas Indonesia. 
Sugiyono. (2015). Metode Penelitian Bisnis. Alfabeta.

Sugiyono. (2017). Metode Penelitian Kuantitatif, Kualitatif, dan R\&D. Alfabeta, CV.

Wahyudi, B. (2015). Manajemen Sumber Daya Manusia. Sulita.

Furtasan Ali Yusuf, et al. (2021). Buku Panduan Penylisan Skrispi, dan Karya Ilmiah. Universitas Bina Bangsa; Serang

https://jawilan.serangkab.go.id/ 